\title{
EFFECT OF LEVEL OF AMPUTATION ON POSTURAL STEADINESS AMONG LOWER EXTREMITY AMPUTEES
}

Arianna Medema, Douglas Henness, Kendra Steinhorst, Robert Moauro, Michael Reuland, Robert Whelan, Shawna Kester, Hamid Bateni*

Physical Therapy Program, Northern Illinois University, DeKalb, IL, USA.

*Email: hbateni@niu.edu

DOI: https://doi.org/10.33137/cpoj.v1i2.32015

\section{INTRODUCTION}

Increased rate of fall, reduced balance confidence and increased fear of falling is reported for lower extremity amputees. ${ }^{1}$ Fall rate also increases at higher levels of amputation ${ }^{1}$. This study aims to compare postural steadiness of different levels of lower extremity amputees through comparison of time and frequency domain variables of postural sway.

\section{METHODS}

Data from six lower extremity amputees (2 unilateral trans-tibial [UTT], 1 bilateral trans-tibial [BTT], 2 unilateral transfemoral [UTF] and 1 unilateral hip disarticulation [UHD]) with the average age of $51 \pm 16$ years was analyzed. Participants were instructed to stand (bare feet - heels together, 5-7 degrees toe-out) on a force platform and were tested for three standing conditions: aeyes open, b- eyes closed and c- standing on Airex 2.5" thick balance pad (www.airex.com). Each test was repeated three times (block randomized). Force platform data were collected for 35 seconds $(\mathrm{Fs}=100)$. Anteroposterior and mediolateral time series data were filtered through a fourth-order zero phase Butterworth low-pass filter with cut-off frequency of $5 \mathrm{~Hz}$. The first $8 \mathrm{sec}$. and last $2 \mathrm{sec}$. of data were cut off to remove any potential lead-in/out effect.

\section{RESULTS}

Mean ML distance COP sway was significantly affected by both level of amputation $(\mathrm{F} 3,5=15.08 \mathrm{P}<.0001)$ and standing condition ( $\mathrm{F} 2,5=7.45 \quad \mathrm{P}=.0017)$. Maximum velocity of $\mathrm{ML}$ and amputation level were also significantly related $(\mathrm{F} 3,5=8.71 \mathrm{P}<.0001)$. Root Mean Square distance from central sway point in medio-lateral direction, which is known to be single best predictor of future falling risk was affected by both level of amputation and standing conditions $(\mathrm{P}=0.0008)$. Total power computed as the integrated area of power spectrum also was significantly affected by both amputation and standing conditions $(\mathrm{p}<.0001)$. Resultant centroidal frequency was affected by level of amputation $(\mathrm{p}=.017)$.

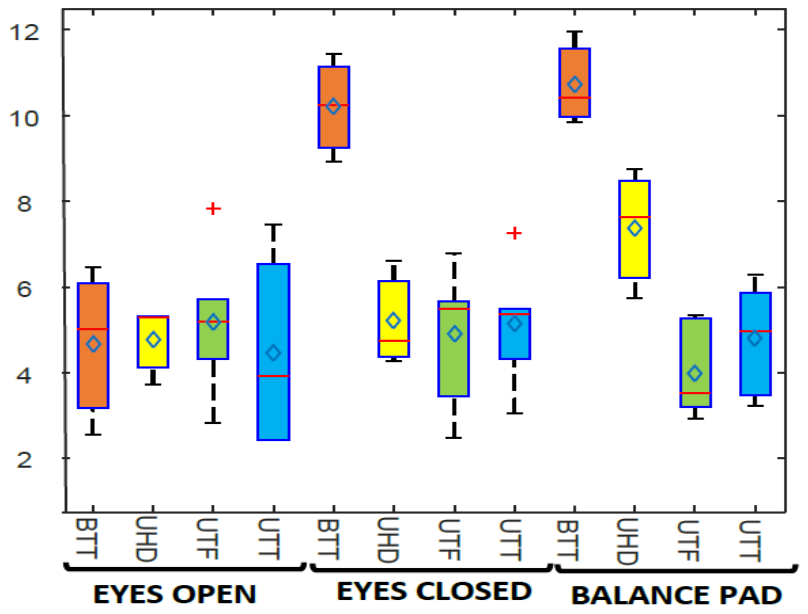

Figure 1: comparison of ML distance of postural sway for different levels of amputation. BTT/UTT=bilateral/unilateral trans-tibial, UTF= unilateral trans-femoral, UHD= unilateral hip disarticulation. Conditions $1=$ eyes open, $2=$ eyes close, $3=$ standing on the foam. Note significant differences between unilateral and bilateral amputees.

\section{CONCLUSION}

Changes in time and frequency domain variables are significantly related to the level of amputation. Variation in frequency domain variable may be indicating application of different strategies in postural steadiness and control of sway.

\section{SIGNIFICANCE}

Impact of level of amputation of frequency domain variables of postural sway may lead to new assessment of prosthetic limb.

\section{REFERENCES}

1- Miller WC et al., The prevalence of risk factors of falling and fear of falling among lower extremity amputees. Arch. Phys. Med. Rehabil. 2001;82: 1031-1037. DOI: $\underline{10.1053 / \mathrm{apmr} .2001 .24295}$

\section{DISCLOSURE}

No conflict of interest exists for this study. 